\title{
Article \\ Automatic Generation Mechanism of Cause-Effect Graph with Informal Requirement Specification Based on the Korean Language
}

\author{
Woo Sung Jang and R. Young Chul Kim *(1)
}

check for updates

Citation: Jang, W.S.; Kim, R.Y.C. Automatic Generation Mechanism of Cause-Effect Graph with Informal Requirement Specification Based on the Korean Language. Appl. Sci. 2021, 11, 11775. https://doi.org/10.3390/ app112411775

Academic Editor: Valentino Santucci

Received: 11 November 2021

Accepted: 7 December 2021

Published: 11 December 2021

Publisher's Note: MDPI stays neutral with regard to jurisdictional claims in published maps and institutional affiliations.

Copyright: (c) 2021 by the authors. Licensee MDPI, Basel, Switzerland. This article is an open access article distributed under the terms and conditions of the Creative Commons Attribution (CC BY) license (https:// creativecommons.org/licenses/by/ $4.0 /)$.
Software Engineering Laboratory, Department of Software and Communication Engineering, Hongik University, Sejong 30016, Korea; jang@selab.hongik.ac.kr

* Correspondence: bob@hongik.ac.kr; Tel.: +82-44-860-2477

\begin{abstract}
In requirement engineering, an important issue is how to transform and tailor the informal system requirements of users or customers into more structured specification documents, which are then used by the software developers. In addition, it is both challenging and necessary to redefine and analyze, from ill-defined or unknown requirements, specifications correctly and automatically generate test cases with them. There are few kinds of research in Korea for automatically reducing requirement complexity and developing test cases of the Korean language-based requirement specifications. Why do we need requirement simplification? Requirement complexity causes analyzers less readability and low understandability. To do this, we propose the automatic cause-effect generation via a requirement simplification mechanism of informal requirement specifications with the Korean language, which works the following procedures: (1) the automatic simplification of informal requirement sentences, (2) the generation of Condition/Conjunction/Clause Tree (C3Tree) Model, (3) and the Cause-effect generation.
\end{abstract}

Keywords: Korean language based requirement specification; requirement analysis; requirement formulation; cause-effect graph

\section{Introduction}

In recent years, software development organizations must balance the need for highquality software through diverse testing technologies [1] and the need to make automatic test case generation and test execution from informal Korean requirements, which can reduce testing time and cost in more efficient testing endeavors [2].

However, due to semantic analysis of requirements based on the Korean language [1] in Korea, it is difficult to automatically generate test cases from informal requirements written with the Korean natural language. So, we are still holding on automatically generating test cases from informal natural Korean language-based requirement specifications. To do this, we suggest an automatic generation mechanism to extract cause-effect from requirements as follows: (1) simplify informal requirements, (2) extract Cause and Effect from them, (3) create C3Tree with the extracted Cause and Effects, (4) generate the cause-effect graph, (5) convert this graph into decision tables, and (6) finally generate test cases based on the decision tables.

Gary E. Mogyorodi [3,4] mentions that the Cause-Effect Graphing is a test case design technique that is performed once requirements have been reviewed for ambiguity, and the Cause-Effect Graphing technique derives the minimum number of test cases to cover $100 \%$ of functional requirements to improve the quality of test coverage. To automatically generate a Cause-Effect Graph from the requirements, we propose a method to simplify the structure of a requirement sentence, identify causes and effects in the simplified sentences, and create a Cause/Conjunction/Clause (C3Tree) Model to express the identified 
information, and transform C3Tree Model to Cause-Effect Graph Model. In this paper, we limit to describing the Cause-Effect Graph via Informal requirement specifications.

This paper is organized as follows. Section 2 mentions related works. Section 3 mentions the method of automatically generating Cause-Effect Graphs from the informal requirements. Section 4 mentions our automatic generation mechanism of the Korean Requirements Analyzer for Cause-Effect Graph. Section 5 mentions a case study using actual missile systems. Finally, the conclusion and future work are mentioned in Section 6.

\section{Related Studies}

\subsection{Cause-Effect Graph}

To make the Cause-Effect Graph, they did mention identifying the smallest functional unit from the requirements specification, which defines the identified units as cause and effect, and pairs them [3]. With Cause-Effect Graph, we can create the minimal test cases to include the maximal testing domain of software requirement, which reduces testing time and cost [3]. Additionally, it can show a logical relationship between the input and output conditions with logical operators-AND, OR, and NOT shown in Figure 1 [5]. (a) means 'If $\mathrm{N} 1=$ true, then $\mathrm{N} 2=$ true'. (b) means 'If $\mathrm{N} 1=$ false, then $\mathrm{N} 2=$ true'$^{\prime}$. (c) means 'If N1 = true or N2 = true, then N3 = true'. (d) means 'If N1 = true and N2 = true, then N3 = true'. The Left node represents "Cause" to show the input conditions, such as the changes within a system. On the contrary, The Right node indicates "Effect" to mean the output conditions, including the state which results from the combination of systematic transformation or causes.

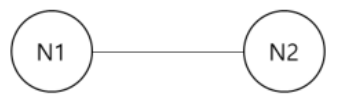

(a) Identity

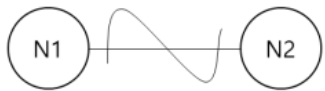

(b) $\operatorname{NOT}(\sim)$

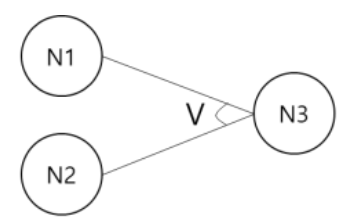

(c) $\mathrm{OR}(\mathrm{v})$

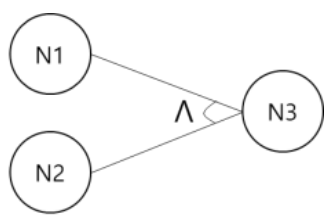

(d) $\operatorname{AND}(\wedge)$

\section{- $\mathbf{N}=$ smallest function element in the system}

Figure 1. Connection Types between the identified Nodes for the Cause-Effect Graph.

Berk Bekirolu [6] focused on testing with the cause-effect graph from English software specifications. Nobody does work with automatically generating Cause-Effect Graphs from the Korean requirements.

\subsection{Model-Based Test Case Generation Research}

Our previous research did follow Gary E. Mogyorodi's approach, which mentioned $100 \%$ functional requirement coverage with the minimal test cases based on a Cause-Effect Graph [3]. We focused on converting sequence diagrams into cause-effect graphs and then generating test cases with them. To automatically make test case generation, we adapted model transformations (such as model-to-model and model-to-text) among models (such as sequence diagram, cause-effect diagram, decision table, and test case) based on the meta-modeling approach [7].

In other words, we transformed (1) a cause-effect graph into a decision table and (2) the decision table into a test case through the model transformation method, which implements the input and output data of the model transformation as all XML metadata exchange [4]. This approach did not deal with informal requirement sentences. Figure 2 shows this process of model transformations.

Each meta model stores meta information about the model (XMI File). The CauseEffect Graph is automatically converted to the Decision Table by Model Transformation Engine 1 with Transformation Rule 1. Model Transformation Engine1 automatically converts the Cause-Effect Graph generated by referring to the Cause-Effect Meta model to the 
Decision Table created by the Decision Table Meta model. Likewise, the Decision Table is automatically converted into a Test case by Model Transformation Engine 2.

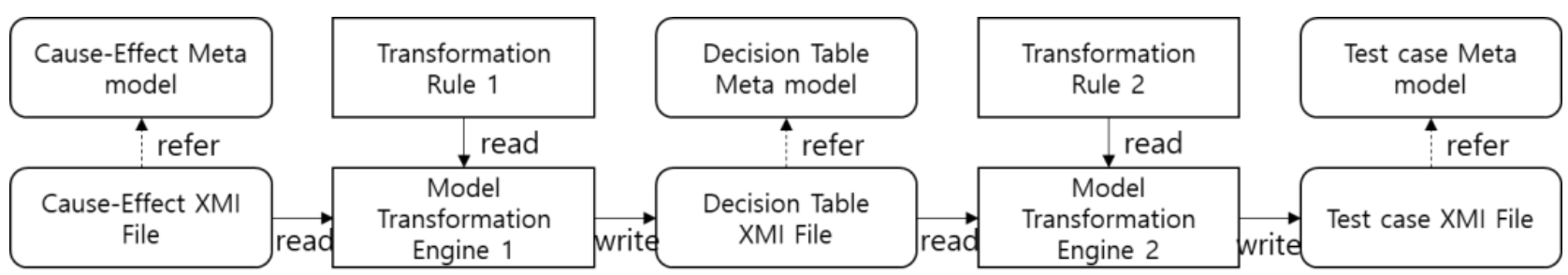

Figure 2. The Model transformations [4].

\section{Automatic Generation Method of the Cause-Effect Graph from Informal Requirement Specifications}

We show the process of a cause-effect graph generation from informal requirement specifications, as shown in Figure 3. We offer the process of a cause-effect graph generation from informal requirement specifications as follows: (1) Informal Korean Requirement Specification as a text file, (2) the Simplified Sentences as program data in memory, (3) C3Tree Model as a simplified text model file, and (4) Cause-Effect Graph as an output model file, and Steps 1-3 as methods for generating each output.

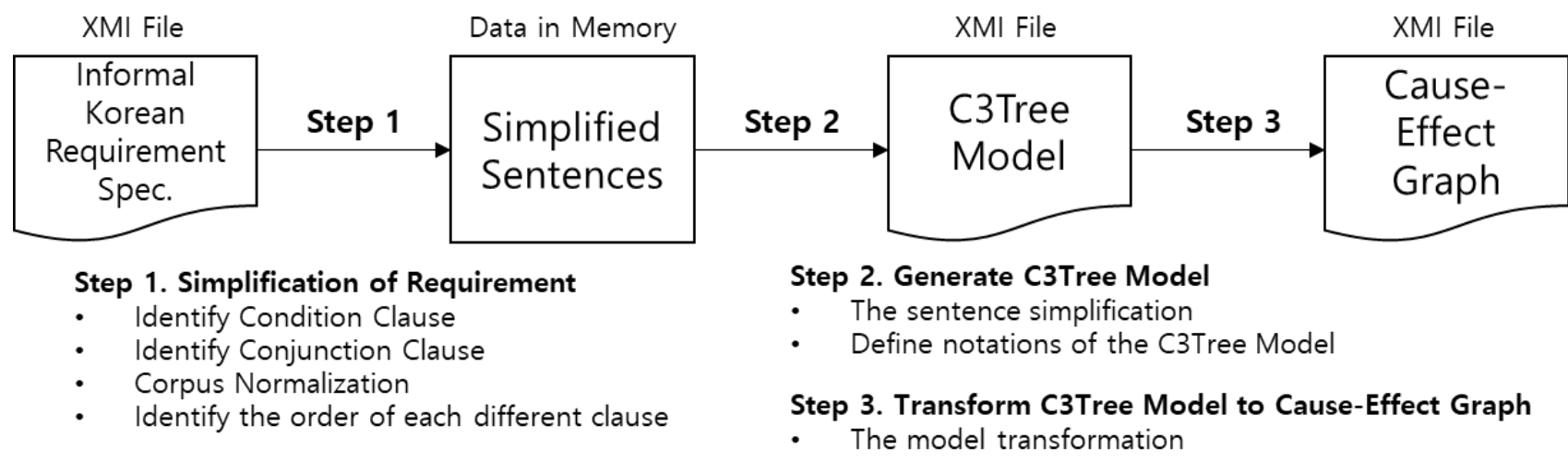

Figure 3. The Process of Cause-Effect Graph Generation from Informal Requirement Spec.

In this process, we simplify the informal requirement sentence and express the C3Tree Model as the simplification. Finally, we represent the C3Tree Model as a CauseEffect Graph.

\subsection{Step 1. Simplify Complex Requirements}

We identify the "Cause" node, "Effect" node with the "Identity" relationship, "NOT" relationship, "AND" relationship, and "OR" relationship between the cause and the effect node in natural language-based requirement sentences. Then we draw a Cause-Effect Graph using the identified information, placing the "Cause" node in the Condition clause and the "Effect" node in the Result clause of a natural language sentence. There exists the "AND" or "OR" relationship between a Conjunction clause and the Following clause nested from each "Cause" and "Effect" node. It can also place the "NOT" relationship in both the Condition clause and Result clause.

We use a morpheme analyzer to analyze the morpheme in a sentence, which identifies the types (condition, result, conjunction, and following) of the Clauses in the sentence included with the analyzed morphemes. The morpheme analyzer represents tags instead of part of speech (POS) to identify morphemes of the sentence. Table 1 shows details of the tags of POS used in the morpheme analyzer. 
Table 1. Parts of POS tags in the Korean language.

\begin{tabular}{cccccc}
\hline Tag & Description & Tag & Description & Tag & Description \\
\hline S & Sentence & VP & Verb phrase & EF & Final ending \\
\hline CDC & Condition Clause & SL & Foreign language & SF & Terminal punctuation \\
\hline RC & Result Clause & JKS & Subjective case marker & VV & VX \\
\hline CJC & Conjunction Clause & NNG & General Noun & Auxiliary verb \\
\hline FC & Following Clause & XSV & Verb derivational suffix & - & - \\
\hline NP_SBJ & Subjective noun phrase & EC & Connective ending & - & - \\
\hline
\end{tabular}

\subsubsection{Identify the Condition-Positive, Condition-Negative Relationship}

We use the identification method to identify condition clauses in natural language sentences as shown in Figure 4. Figure 4 consists of two clauses in the sentence. In Korean, the clauses are separated with a Connective Ending (EC). The EC as an original Korean morpheme is added at the end of Clause. The EC has diverse forms of simple and complex types.

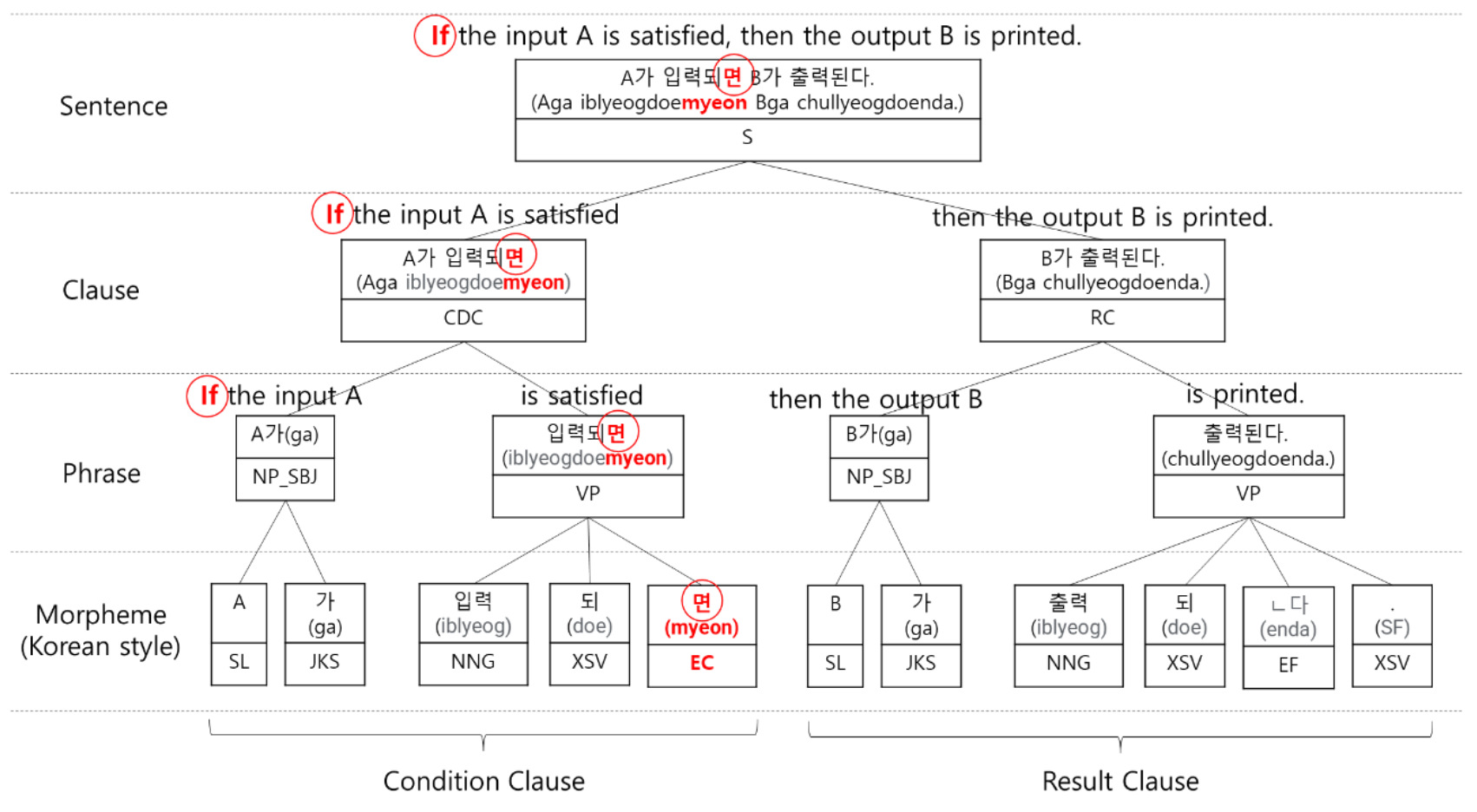

Figure 4. Identification of conditional clauses.

Tables 2 and 3 show the types of EC for condition clauses. The Simple type means the simple EC type with a conditional meaning. The Complex type means combinations of some simple types. An Opened condition mentions the conditions of uncertain facts. A Closed condition means the conditions of certain facts. A Positive condition means the condition of true content. A Negative condition means the condition of false content. The Negative condition is expressed as a NOT relationship in the Cause-Effect Graph. As a result, as in Tables 2 and 3, the clauses with the Connective Ending (EC) are Condition clauses, and the following clause of the condition clause is likely to be the result clause. 
Table 2. Part of Connective ending (EC) types [8] in the Korean language.

\begin{tabular}{crc}
\hline Connective Ending (EC) Type & EC Forms (Korean) & English Description \\
\hline Simple type & -면(Myun), - 거든(Geodeun), -어 야(Uya) & Simple IF statements \\
Complex type & -다면(Damyeon), -은들(Eundeul), - 다가(Daga), -든지(Deunji), & Nested IF statements \\
& -려 면(Lyeomyeon), - 거드면(Geodeumyeon), - 거들 & \\
\hline
\end{tabular}

Table 3. Part of Condition types [8] in the Korean language.

\begin{tabular}{|c|c|c|c|}
\hline Condition Type & Subtype & EC Forms (Korean) & English Description \\
\hline Opened condition & - & -면(Myun), - 거든(Geodeun), ... & It means conditions of uncertain facts. \\
\hline \multirow{2}{*}{ Closed condition } & Positive condition & -아(A)/어(Uh)/ 여야(Uya),... & $\begin{array}{l}\text { It means conditions of certain facts. } \\
\text { The Result is positive (true). }\end{array}$ \\
\hline & Negative condition & -던들(Deondeul), ... & $\begin{array}{l}\text { It means conditions of certain facts. } \\
\text { The result is negative (false). }\end{array}$ \\
\hline
\end{tabular}

\subsubsection{Identify the Conjunction-AND, Conjunction-OR Relationship}

The identification method of conjunction clauses in natural language sentences is shown in Figure 5. The sentence consists of two clauses. Table 4 describes the types of Connective Endings for the Conjunction clause. The clauses that contain the Connective Ending (EC) of Table 4 are Conjunction clauses. The next clause of the conjunction clause is the following clause.

Additionally, we identify "AND" and "OR" through the connective ending (EC) for the conjunction clause. Table 5 shows the identification process. As a result, the conjunction clause and the following clause of Causality Relationship, Sequential relationship, Parallel relationship, Time relationship, Cause and Reason Relationship, Purpose and Intention Relations, and Conversion Relationship have an "AND" relationship. The conjunction clause and the following clause of Contrast Relationship, Selection Relationship, and Concession Relationship have an "OR" relationship.

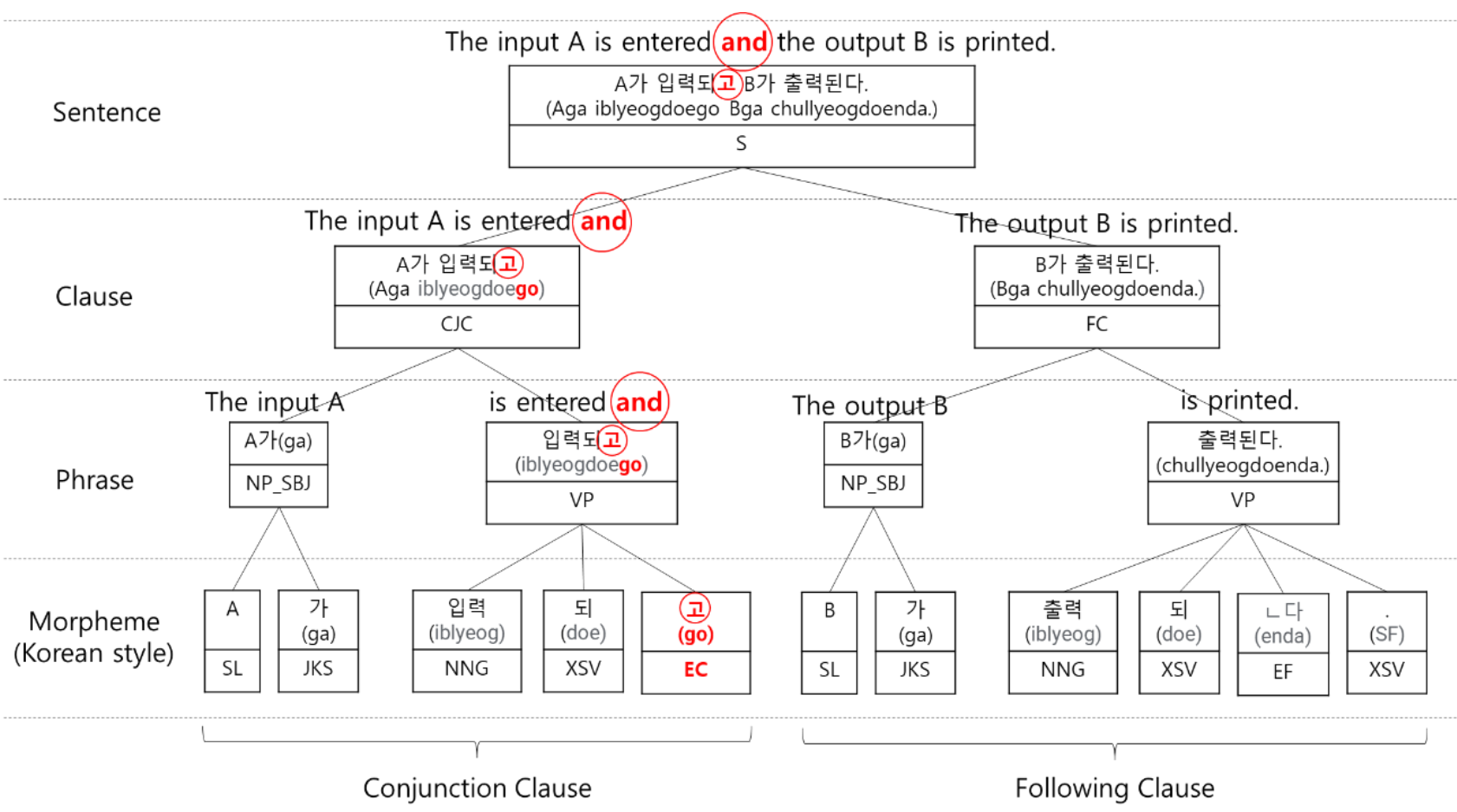

Figure 5. Identification of conjunction clauses. 
Table 4. Parts of Combination Types between Conjunctions.

\begin{tabular}{|c|c|c|}
\hline Conjunction Type & EC Forms [9-11] (Korean) & English Description \\
\hline Causality Relationship & '-느라고(Nerago),' Etc. & $\begin{array}{c}\text { If } \mathrm{B} \text { for } \mathrm{A} \text {, then } \mathrm{C} . \\
(\mathrm{A}=\text { true, } \mathrm{B}=\text { true, } \mathrm{C}=\text { true })\end{array}$ \\
\hline Sequential relationship & '-고(Go)(서(Seo)),' Etc. & $\begin{array}{c}\text { If } \mathrm{B} \text { after } \mathrm{A} \text {, then } \mathrm{C} . \\
(\mathrm{A}=\text { true }, \mathrm{B}=\text { true }, \mathrm{C}=\text { true })\end{array}$ \\
\hline Parallel relationship & $\begin{array}{c}\text { '-고(Go),' '-(으 }(\mathrm{Eu})) \text { 며 }(\mathrm{Myeo}),{ }^{\prime} \text { '-(으(Eu)면 } \\
\text { 서(Myeonseo),' Etc. }\end{array}$ & $\begin{array}{l}\text { If } \mathrm{A} \text { and } \mathrm{B} \text { are at the same time, then } \mathrm{C} \text {. } \\
\qquad(\mathrm{A}=\text { true, } \mathrm{B}=\text { true }, \mathrm{C}=\text { true })\end{array}$ \\
\hline Contrast Relationship & '-(으(Eu))나(Na),' '-지만(Jiman),' Etc. & $\begin{array}{c}\text { If } A \text { and } B \text {, then } C \\
(A=\text { false, } B=\text { true, } C=\text { true })\end{array}$ \\
\hline
\end{tabular}

Table 5. Parts of Logical Expression of Conjunction.

\begin{tabular}{ccc}
\hline Conjunction Type & $\begin{array}{c}\text { Mathematical } \\
\text { Expression }\end{array}$ & $\begin{array}{c}\text { A Logical Combination of A and } \\
\text { B for C }=\text { True }\end{array}$ \\
\hline $\begin{array}{c}\text { Causality } \\
\text { Relationship }\end{array}$ & B:A- $>$ C & AND \\
\hline $\begin{array}{c}\text { Sequential } \\
\text { relationship }\end{array}$ & A:B- $>C$ & AND \\
\hline Parallel relationship & A | | B- $>C$ & AND \\
\hline $\begin{array}{c}\text { Contrast } \\
\text { Relationship }\end{array}$ & $\neg$ A:B- $>C$ & OR \\
\hline
\end{tabular}

\subsubsection{Corpus Normalization}

We use corpus normalization [9-11] to automatically convert a sentence with a passive meaning into a sentence with an active substance. These include 1) changing the passive sentence to the active sentence and 2) changing the causative sentence to the active sentence. It is challenging to analyze the meaning of informal sentences. In the case of Korean, it is difficult to identify the subject and object in the passive sentences. That is why we convert passive sentences into active sentences. In other words, if the sentence contains an ambiguous subject and object, we can recognize the clear subject and object through corpus normalization. This method changes the form or position of a case marker in the sentence. The case marker is only one of the morphemes in the Korean language. For example, the case marker '가(ga)' is also only the Korean morpheme. The 'A 가(ga)' means that a subject ' $A$ ' and a case marker '가(ga).' Therefore, we represent the case marker '가(ga)' after a noun 'A' in Figure 5. The subject word in Korean Sentence admits any front position of a sentence, unlike English sentences, such as 'Subject = word + subject case marker' and 'Object $=$ word + object case marker.' A subject and an object are determined according to the type of case marker. As a result, the form and position of the case marker are changed, then the subject can be changed to the object. An Underlined is a case marker. Table 6 shows the example case.

Table 6. One Example of Converting Passive Sentence to Active Sentence.

\begin{tabular}{cccc}
\hline \multicolumn{2}{c}{ Passive Sentence } & \multicolumn{2}{c}{ Active Sentence } \\
\hline Korean & English & Korean & English \\
\hline $\begin{array}{c}\text { 그들에 의해 협상이 깨어지다. } \\
\text { (geudeul-e uihae hyeobsang-i } \\
\text { kkaeeojida.) }\end{array}$ & Negotiations are broken by them. & $\begin{array}{c}\text { 그들이 협상을 깨다. (geudeul-i } \\
\text { hyeobsang-eul kkaeda.) }\end{array}$ & $\begin{array}{c}\text { They break } \\
\text { negotiations. }\end{array}$ \\
\hline
\end{tabular}




\subsubsection{Identify the Order of Each Different Clause}

We propose a clause order recognition method for identifying each clause's priority of connective endings (ECs) in a sequential or composited sentence. In Figure 6, we show our clause order algorithm for determining the priority of each connective ending (EC) of clauses in a sentence as follows: In the first step, identify all kinds of ECs and the number of ECs in the sentence, in the second step, classify condition clause/result clause or conjunction clause/result clause. Until not including any EC in the sentence, the whole sentence crumbles into fractions, that is, morphemes of phases of clauses of one sentence.

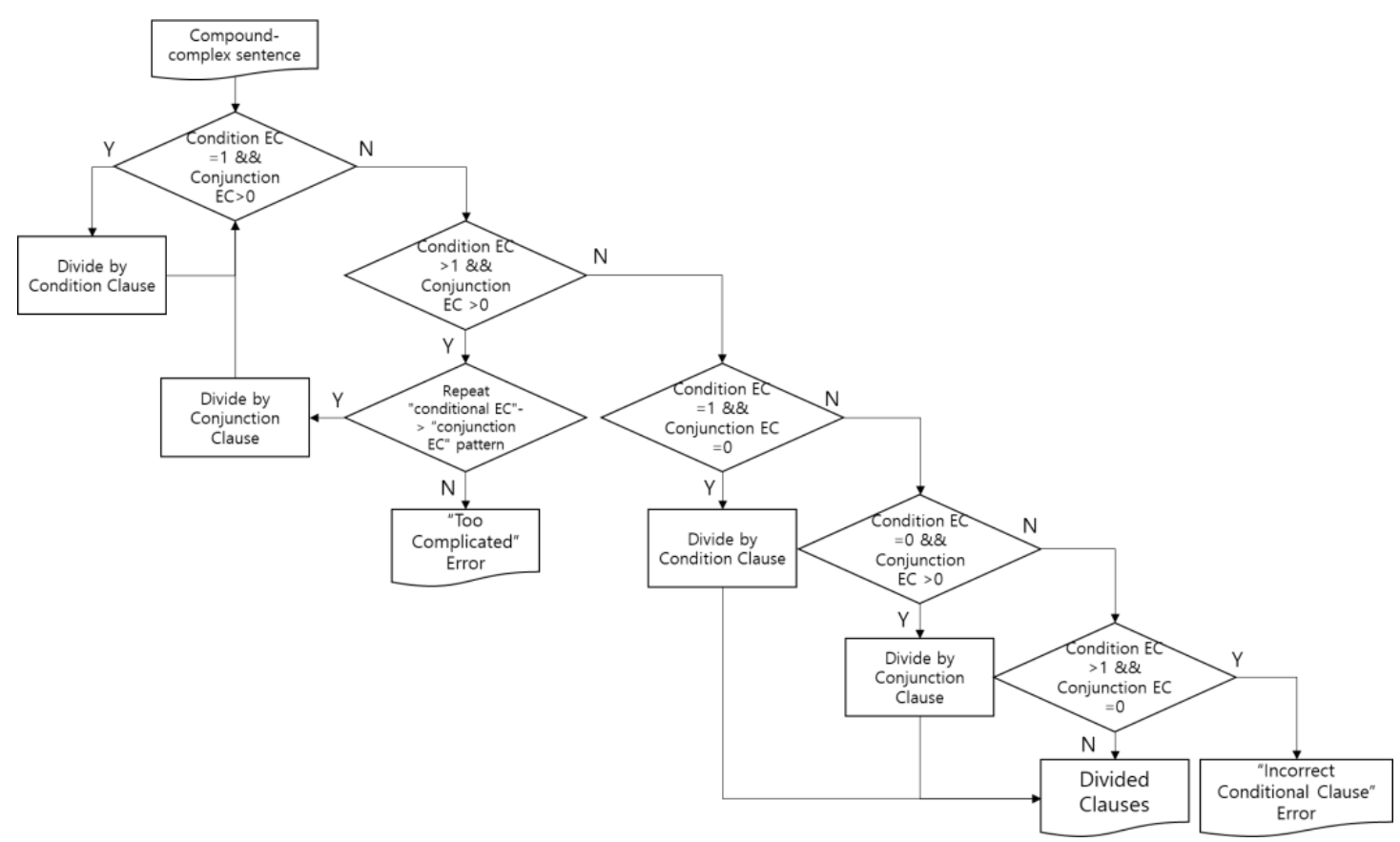

Figure 6. The clause order algorithm for identifying the priority of each connective ending $(\mathrm{EC})$ of clauses in a sentence.

In Figure 7, we identify three clauses $(\mathrm{C} 1, \mathrm{C} 2, \mathrm{C} 3)$ with the connective ending (EC) of the morphemes after identifying the morphemes in the sentence. When we adopt the clause order algorithm with three clauses C1, C2, and C3 in Figure 7, we can locate the 'AND' relationship between $\mathrm{C} 1$ and $\mathrm{C} 2$ and identify the 'IF-Then' relationship between C3 and ' $\mathrm{C} 1 \cap \mathrm{C} 2$ '.

Figure 8 shows four clauses $(\mathrm{C} 1, \mathrm{C} 2, \mathrm{C} 3$, and $\mathrm{C} 4)$ in a sentence. By applying the clause order algorithm with four clauses C1, C2, C3, and C4, in Figure 8, we can identify the 'IF-Then' relationship between C1 and C2 and identify the 'IF-Then' relationship between C3 and C4. Finally, place the 'AND' relationship between them.

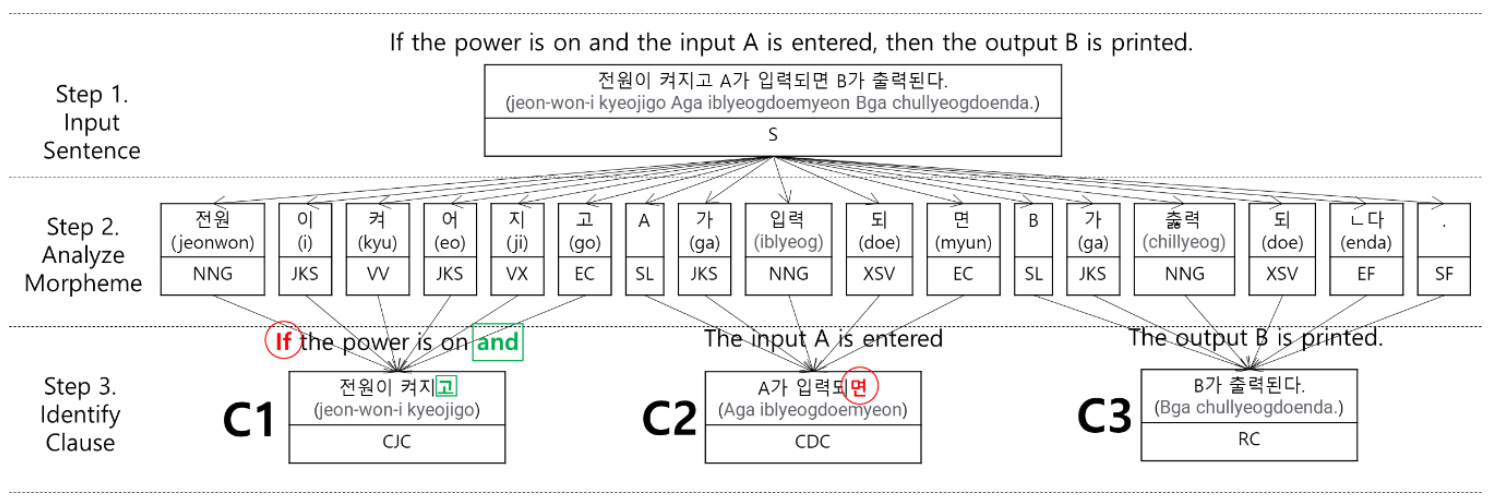

Figure 7. One example of identifying the priority of clauses in a simple sentence. 
If The input $A$ is entered, then the output $B$ is printed, and if the input $C$ is entered, then the output $D$ is printed.

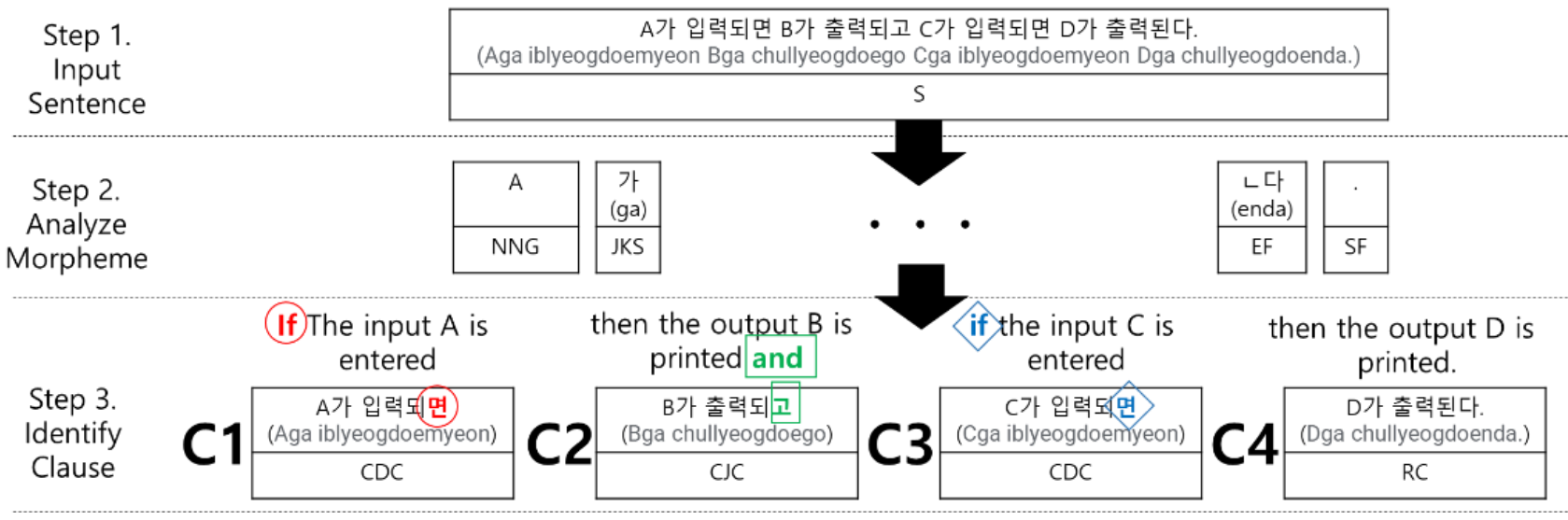

Figure 8. One example of identifying the priority of clauses in a composite sentence.

We mention the clauses of natural language sentences combined in various ways, for example, sentence complexity with diverse clause combinations. However, we consider some limited formulas of clause identification patterns within Table 7.

Table 7. Types of identifiable clause patterns.

\begin{tabular}{cccccc}
\hline Pattern & Formula & Identification Clause & Pattern & Formula & Identification Clause \\
\hline 1 & $\sum_{\mathbf{n}=\mathbf{1}}^{\infty}\left(\boldsymbol{C} \boldsymbol{F}_{\boldsymbol{n}}\right)$ & CF identification & 4 & $\sum_{n=1}^{\infty}\left(C R_{n}+C F_{n}\right)$ & $\begin{array}{c}\text { CF identification after } \\
\text { CR identification }\end{array}$ \\
\hline 2 & $\sum_{\boldsymbol{n}=\mathbf{1}}^{\infty}\left(\boldsymbol{C R}_{\boldsymbol{n}}\right)$ & CR identification & 5 & $\sum_{\boldsymbol{n}=1}^{\infty}\left(\boldsymbol{C} \boldsymbol{F}_{\boldsymbol{n}}\right)+\boldsymbol{C} \boldsymbol{R}+\sum_{\boldsymbol{n}=\mathbf{1}}^{\infty}\left(\boldsymbol{C} \boldsymbol{F}_{\boldsymbol{n}}\right)$ & $\begin{array}{c}\text { CF identification after } \\
\text { CR identification }\end{array}$ \\
\hline 3 & $\sum_{n=1}^{\infty}\left(C F_{n}+C R_{n}\right)$ & $\begin{array}{c}\text { CR identification after } \\
\text { CF identification }\end{array}$ & 6 & $\sum_{\boldsymbol{n}=\mathbf{1}}^{\infty}\left(\boldsymbol{C R}_{\boldsymbol{n}}\right)+\boldsymbol{C} \boldsymbol{F}+\sum_{\boldsymbol{n}=\mathbf{1}}^{\infty}\left(\boldsymbol{C} \boldsymbol{R}_{\boldsymbol{n}}\right)$ & $\begin{array}{c}\text { CR identification after } \\
\text { CF identification }\end{array}$ \\
\hline
\end{tabular}

$\mathrm{CF}=$ Conjunction Clause + Following Clause, $\mathrm{CR}=$ Conditional Clause + Result Clause.

\subsection{Step 2. Generate C3Tree Model}

We define C3Tree Model (like a tree structure) to convert a simplified sentence into a complex sentence.

\subsubsection{Do Simplification Method}

First, we store 'the original complex sentence' into the top node root of this Model. Second. We also save the simplified sentence into the bottom nodes of the tree model. Third, until not is any condition and conjunction clause in the sentence, we repeatedly separate into condition clause and result clause if having any EC in the condition clause of a sentence or split into conjunction clause and the following clause if including any EC in the conjunction clause of a sentence.

\subsubsection{Define Notations of the C3Tree Model}

The C3Tree Model consists of nodes and links for visualizing the sentence simplification. That is, we divide a long and complex sentence into some short sentences. Table 8 shows nodes and links of the C3Tree Model.

The C3Tree Model is expressed by XMI code. Table 9 is an example of the C3Tree Model XMI code. 
Table 8. C3Tree Notation.

\begin{tabular}{|c|c|c|c|}
\hline Node & Description & Link & Description \\
\hline $\begin{array}{l}\text { <<Sentence>> } \\
\text { Korean Sentence }\end{array}$ & Sentence & & $\begin{array}{l}\text { Positive condition link (If left node = } \\
\text { true, right node }=\text { true })\end{array}$ \\
\hline $\begin{array}{l}<<\text { Clause }>> \\
\text { Korean Sentence }\end{array}$ & Clause in sentence & & $\begin{array}{l}\text { Negative condition link }(\text { If left node }= \\
\text { true, right node }=\text { false })\end{array}$ \\
\hline $\begin{array}{c}<<\text { Complex-Clause }> \\
\text { Korean Sentence }\end{array}$ & $\begin{array}{l}\text { The complex clause in a sentence } \\
\text { (includes two or more child nodes) }\end{array}$ & & $\begin{array}{l}\text { AND conjunction link (If all child } \\
\text { nodes }=\text { true, parent node }=\text { true })\end{array}$ \\
\hline- & - & & $\begin{array}{l}\text { OR conjunction link (If one of the child } \\
\text { nodes = true, parent node }=\text { true) }\end{array}$ \\
\hline
\end{tabular}

Table 9. XMI Code of C3Tree Model Example.

C3Tree Model

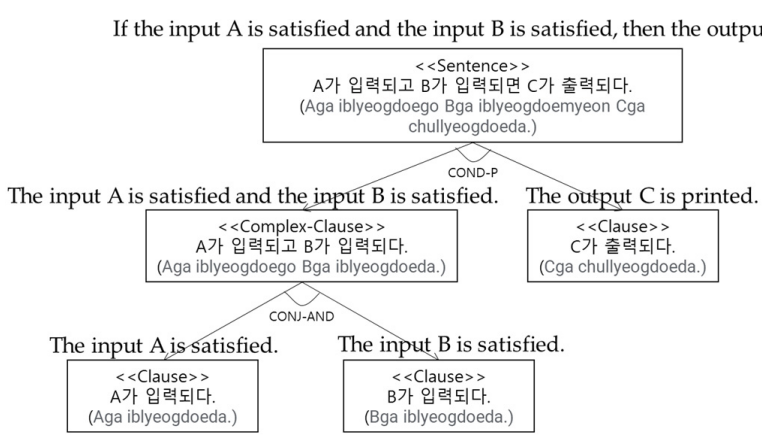

$<$ node $\mathrm{ctid}=$ " 1 " type $=$ "sentence" string="A가 입력되고 B가 출력되면 C가 출력되다."/>

$<$ node ctid $=$ "2" type $=$ "cclause"

string="A가 입력되고 B가 입력되다."/>

$<$ node ctid=" 3 " type $=$ "clause"

string $=$ "C가 출력되다." />

$<$ node ctid $=$ " 4 " type $=$ "clause"

string="A가 입력되다."/>

$<$ node ctid $=$ " 5 " type $=$ "clause"

string="B가 입력되다." />

$<$ link type $=$ "condp" parent $=$ " 1 " left $=$ " 2 "

right $=" 3$ " $/>$

$<$ link type $=$ "conjand" parent $=$ " 2 " left $=$ " 4 "

right $=" 5 " />$
$<$ node $\operatorname{ctid}=$ " 1 " type $=$ "sentence" string $=$ "If the input $A$ is satisfied and the input $B$ is satisfied, then the output $C$ is printed." /> $<$ node ctid $=$ " 2 " type $=$ " clause" " string $=$ "The input $\mathrm{A}$ is satisfied and the input $\mathrm{B}$ is satisfied." /> $<$ node ctid $=$ " 3 " type $=$ "clause" string $=$ "The output $C$ is printed." /> $<$ node ctid $=$ " 4 " type $=$ "clause" string $=$ "The input A is satisfied." /> $<$ node ctid $=$ " 5 " type $=$ "clause" string $=$ "The input B is satisfied." /> $<$ link type $=$ "condp" parent $=$ " 1 " left $=$ " 2 " right $=$ " 3 " / >

$<$ link type $=$ "conjand" parent $=$ " 2 " left $=$ " 4 " right $=" 5 " />$

\subsection{Transform C3Tree Model to Cause-Effect Graph}

In this section, we transform the notations of C3Tree Model notation into the notation of the Cause-Effect Graph. Therefore, a $<<$ Clause $>>$ node of the C3Tree Model is transformed into a $<<$ Node $>>$ in the Cause-Effect Graph. In Table 10, we show the transformation relationship between C3Tree Model and Cause-Effect Graph.

Figure 9 is an example of the transformation process. First, five $<<$ Clause $>>$ nodes at the bottom level of C3TREE are transformed to N1 N5 of a cause-effect graph. The left node of COND-J is transformed to the Cause node. The right node of COND-J is transformed as the Effect node. CONJ-AND is transformed to AND. "The output C is printed" node of the left tree and "The output $C$ is printed" node of the right tree has the same sentence. Therefore, the "The output $C$ is printed" node of the left tree and "The output $C$ is printed" node of the right tree are integrated into N3. 
Table 10. Relationship between C3Tree Model Notations and Cause-Effect Graph Notations.

\begin{tabular}{ccc}
\hline Case & C3Tree Model Notation & Cause-Effect Graph Notation \\
\hline 1 & Clause & Node \\
\hline 2 & CONJ-AND & AND \\
\hline 3 & CONJ-OR & OR \\
\hline 4 & The left child node of COND-P(COND-N) & Cause \\
\hline 5 & The right child node of COND-P(COND-N) & Effect \\
\hline 6 & COND-P & Identity \\
\hline 7 & COND-N & NOT \\
\hline
\end{tabular}

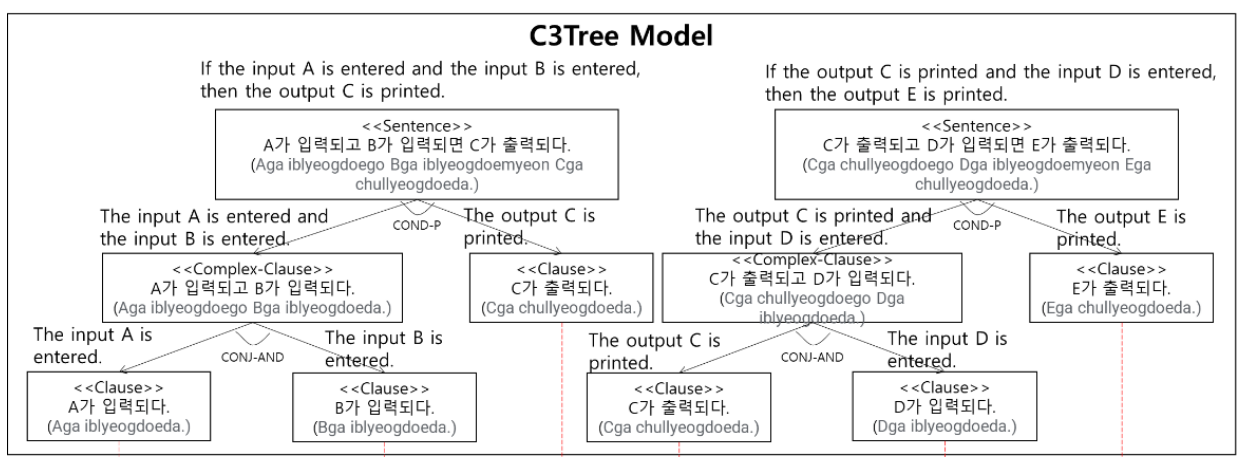

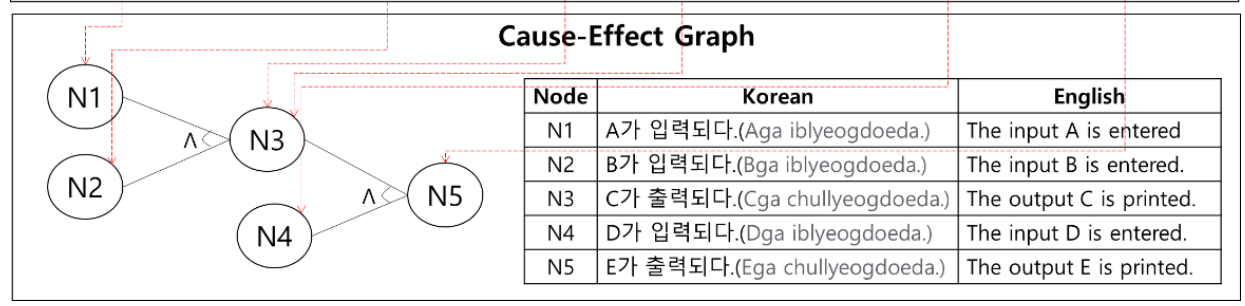

Figure 9. The transformation process of Cause-Effect Graph from C3Tree Model.

The Cause-Effect Graph is expressed in XMI code. Table 11 is the XMI code for Cause-Effect Graph in Figure 9.

Table 11. XMI Code of Cause-Effect Graph.

\begin{tabular}{|c|c|}
\hline XMI Code (Korean) & XMI Code (English) \\
\hline 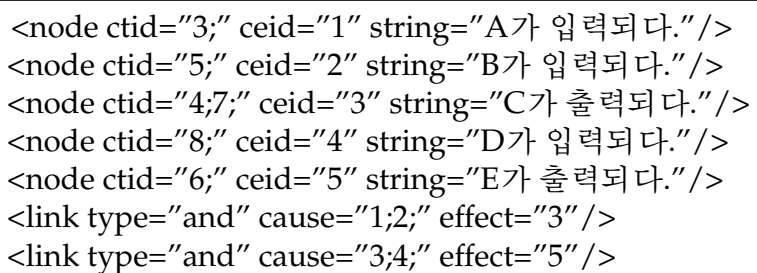 & 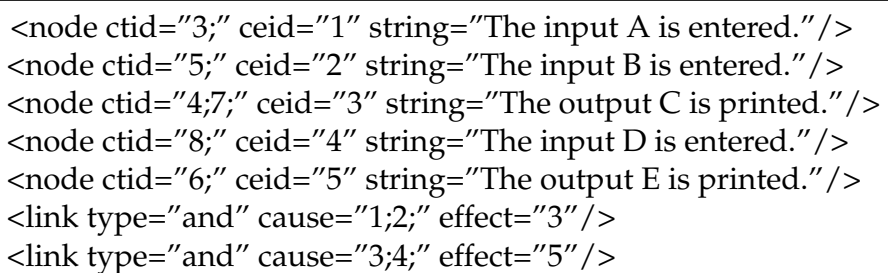 \\
\hline
\end{tabular}

\section{Automatic Generation Mechanism}

We suggest the automatic generation mechanism mentioned in chapter 3 . That is, we describe the procedure of the automatic generation mechanism with informal requirements sentences and then generate a Cause-Effect Graph as follows: (1) Input the Korean language sentence, (2) Analyze morpheme in a sentence, (3) Identify cause using EC morpheme, (4) Convert clauses to sentences, (5) Convert passive sentence to active sentence, (6) Integration similar sentences, (7) Generate Cause-Effect Graph. Figure 10 shows the detailed procedure of the generation process. 

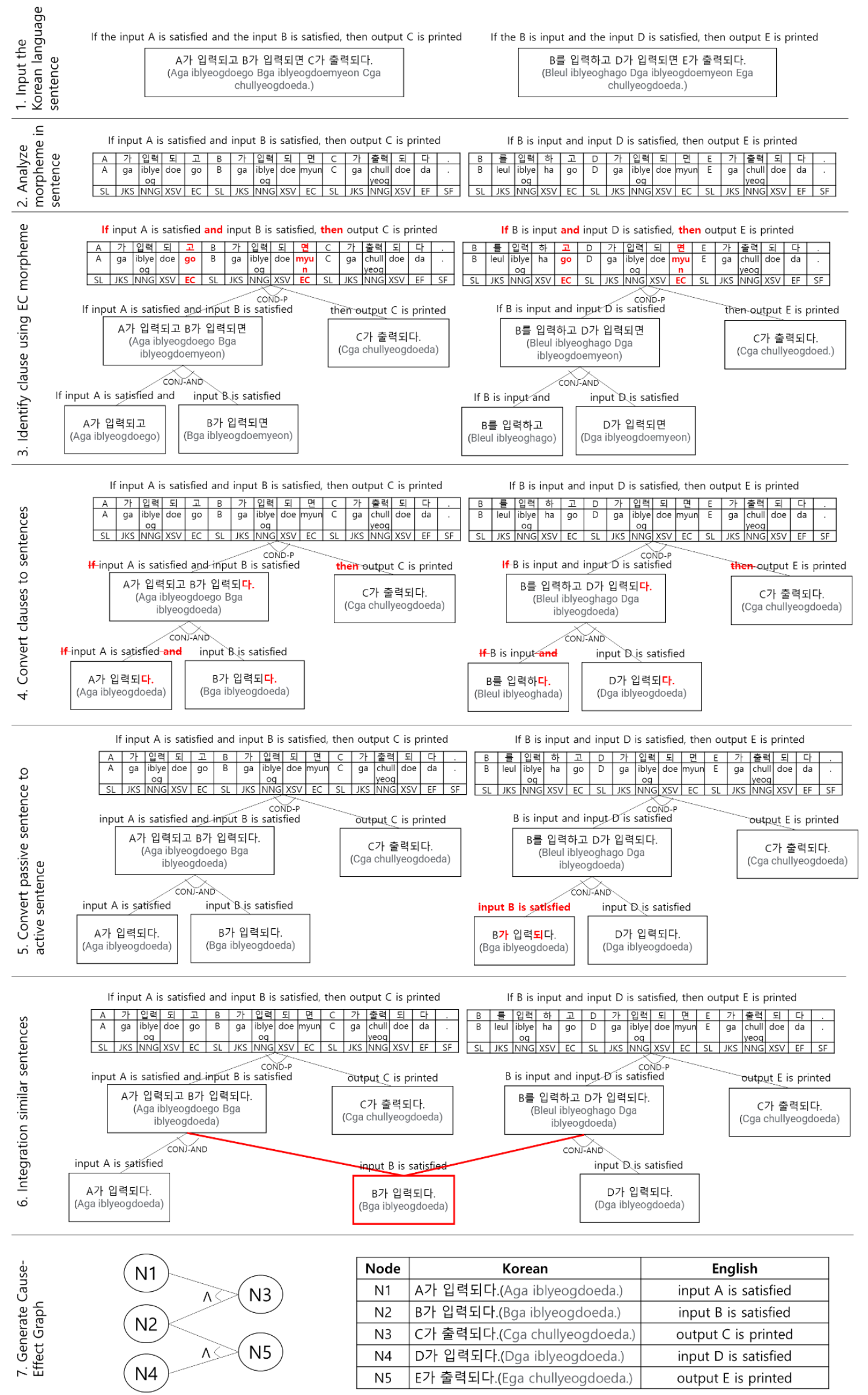

Figure 10. Our automatic generation mechanism of the Korean Requirements Analyzer for Cause-Effect Graph. 


\section{A Case Study}

We explain our mechanism with real requirements of 'A guidance for completing DPS for a Missile system [12]. Figure 11 is part of the requirement specifications (R1.1.7 communications) in the missile system.

\section{R1}

When the air vehicle becomes the node in the net and performs networking, command and control, and combat space awareness, the data transmission and reception functions for air traffic management are implemented.

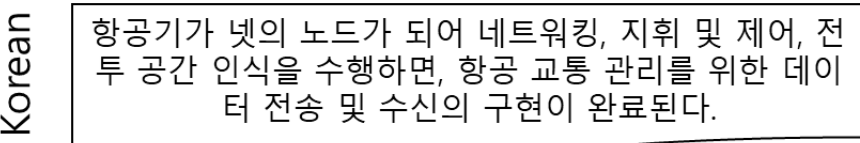

\section{R2}

If the antenna assembly or assembly comprises the communication subsystem and data transmission and reception functions for air traffic management are implemented, the level 3 element is completed.

통신 하위 시스템에 안테나 어셈블리 또는 어셈블리 가 적용되고, 항공 교통 관리를 위한 데이터 전송 및 수신 기능이 구현되었다면, 레벨 3 요소가 완료된다.

Figure 11. Requirement specifications in the missile system.

Figure 12 is the C3Tree Model generated from the requirement specification. Four $<<$ Clause $>>$ were generated.

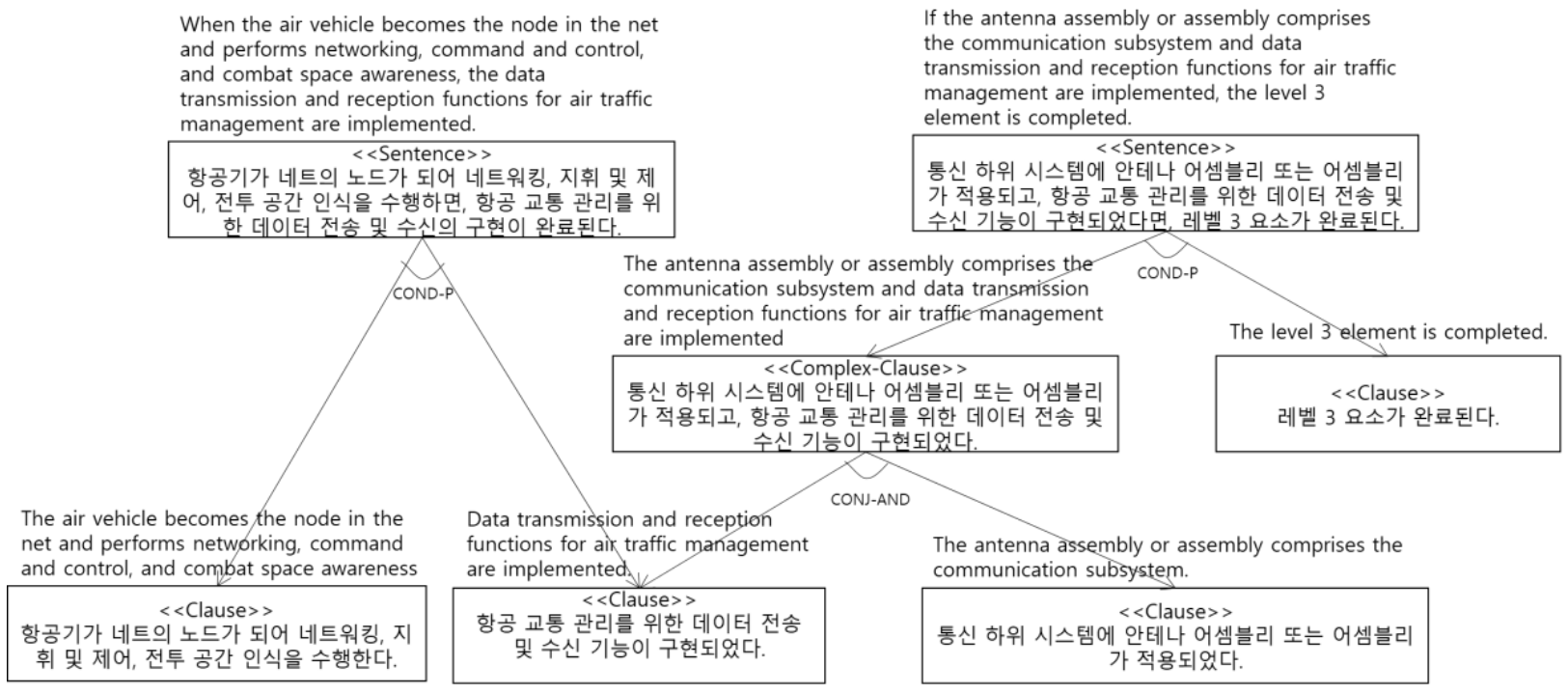

Figure 12. C3Tree Model generated from Requirement specifications.

Figure 13 is the Cause-Effect Graph generated from the C3Tree Model. Four $<<$ Clause $>>$ are changed to nodes.

Cause-Effect Graph

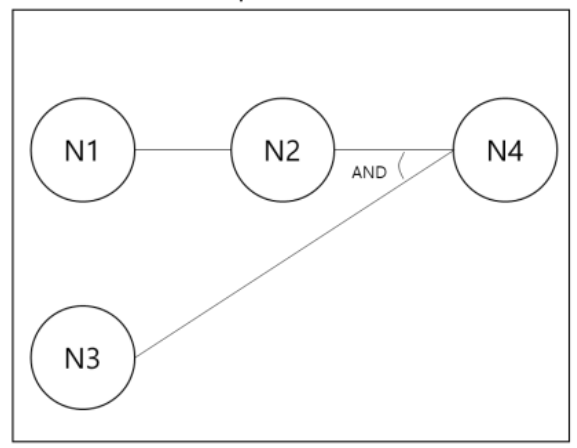

Causes and Effects

\begin{tabular}{|c|l|l|}
\hline Node & \multicolumn{1}{|c|}{ Korean } & \multicolumn{1}{c|}{ English } \\
\hline N1 & $\begin{array}{l}\text { 항공기가 네트의 노드가 되 } \\
\text { 어 네트워킹, 지휘 및 제어, } \\
\text { 전투 공간 인식을 수행한다. }\end{array}$ & $\begin{array}{l}\text { The air vehicle becomes the node in the net } \\
\text { and performs networking, command and } \\
\text { control, and combat space awareness }\end{array}$ \\
\hline N2 & $\begin{array}{l}\text { 항공 교통 관리를 위한 데 } \\
\text { 이터 전송 및 수신 기능이 } \\
\text { 구현되었다. }\end{array}$ & $\begin{array}{l}\text { Data transmission and reception functions } \\
\text { for air traffic management are implemented. }\end{array}$ \\
\hline N3 & $\begin{array}{l}\text { 통신 하위 시스템에 안테나 } \\
\text { 어셈블리 또는 어셈블리가 } \\
\text { 적용되었다. }\end{array}$ & $\begin{array}{l}\text { The antenna assembly or assembly } \\
\text { comprises the communication subsystem. }\end{array}$ \\
\hline N4 & 레벨 3 요소가 완료된다. & The level 3 element is completed. \\
\hline
\end{tabular}

Figure 13. Cause-Effect Graph generated from C3Tree Model. 


\section{Conclusions and Future Research}

Our software industries ask us to automatically generate test cases with only informal Korean requirement documents in the Korea academy. Until now, none consider test case generation with informal Korean requirements. We focus on automatically generating test cases from requirements. As our first step, we propose a mechanism for automatically transforming requirements into the Cause-Effect Graphs as an intermediate process for generating test cases from informal requirement specifications written in the Korean language. To do this, we define our C3Tree structure for converting complex and lengthy sentences to simplified and short sentences, which are generated by applying a formal sentence analysis method with requirements and provided traceability of intermediate changing steps between the original sentence and a Cause-Effect Graph. As a case study, we apply the proposed mechanism with actual requirements of the Defined Pricing Structure (DPS) for a Missile system.

In future work, we should develop our tool for dealing with a vast requirement, which effectively and automatically transforms test cases via the Cause-Effect Model from informal requirement sentences.

Author Contributions: W.S.J. and R.Y.C.K. designed the present study, reviewed the literature, and drafted the manuscript; W.S.J. and R.Y.C.K. performed the verification of the model generation process; W.S.J. and R.Y.C.K. critically revised the manuscript. All authors have read and agreed to the published version of the manuscript.

Funding: This work was supported by the National Research Foundation (NRF), Korea, under project BK21 FOUR (F21YY8102068), and also by Basic Science Research Program through the National Research Foundation of Korea (NRF) funded by the Ministry of Education (2021R1I1A305040711).

Institutional Review Board Statement: Not applicable.

Informed Consent Statement: Not applicable.

Conflicts of Interest: The authors have no conflict of interest.

\section{References}

1. Kwon, O.S.; Hong, S.N. Effective iterative testing based on log. In Proceedings of the Korea Society of Management Information Systems Fall Conference, Seoul, Korea, 13 November 2009; pp. 685-690.

2. Shepperd, M.; Ince, D. Derivation and Validation of Software Metrics; Oxford Science Publications: Oxford, UK, 1993.

3. Mogyorodi, G.E. Requirements-Based Testing-Cause-Effect Graphing; In Software Testing Services: ON, Canada, 2005.

4. Son, H.S.; Park, Y.B.; Kim, R.Y.C. Test case Generation from Cause-Effect Graph based on Model Transformation. In Proceedings of the 2014 International Conference on Information Science \& Applications (ICISA), Seoul, Korea, 6-9 May 2014; pp. 591-593.

5. Myers, G.L. The Art of Software Testing; John Wiley \& Sons, Inc.: Hoboken, NJ, USA, 1979.

6. Bekiroglu, B. A Cause-Effect Graph Software Testing Tool. Eur. J. Comput. Sci. Inf. Technol. 2017, 5, 11-24.

7. Woo, S.; Son, H.; Kim, W.; Kim, J.; Kim, R.Y. A Study Testcase Extraction based M\&S for Pre-Testing. Korea Conf. Softw. Eng. 2012, $14,181-183$.

8. Ha, J.M. A Contrastive Study on Korean Conditional Connective Ending and Chinese Conditional Conjunction Expression; Kyunghee University: Seoul, Korea, 2007.

9. Cho, J.M.; Cho, Y.H.; Kim, G.C. A Corpus Formalization for Extracting the Syntactic Relations. In Proceedings of the 8th Annual Conference on Human \& Cognitive Language Technology, Daejeon, Korea, 11 October 1996; pp. 207-215.

10. Cho, J.M.; Kim, G.C. A Corpus Formalization for Extracting the Syntactic Relations. Korean Soc. Cogn. Sci. 1996, 7, 39-56.

11. Kim, K.A. Comparative Study on Conjoined Sentence between Modern Mongolian and Korean. Korean Assoc. Mong. Stud. 2009, $27,151-186$

12. Guidance for Completing DPS for a Missile System. Available online: https://www.gov.uk/government/uploads/system/ uploads/attachment_data/file/437322/DPS_principles_guidance.PDF (accessed on 1 November 2021). 